Original paper

\title{
Association between interleukin 6 polymorphisms (rs1800796, rs1800795, rs2069837, rs17147230, and rs1800797) and hepatocellular carcinoma susceptibility: a meta-analysis
}

\author{
Omid Emami Aleagha ${ }^{1,2}$, Pembe Oltulu33, Masoud Sadeghi ${ }^{4}$ \\ 'Molecular Pathology Research Center, Imam Reza Hospital, Kermanshah University of Medical Sciences, Kermanshah, Iran \\ ${ }^{2}$ Clinical Research Development Center, Imam Reza Hospital, Kermanshah University of Medical Sciences, Kermanshah, Iran \\ ${ }^{3}$ Pathology Department, Meram Faculty of Medicine, Necmettin Erbakan University, Konya, Turkey \\ ${ }^{4}$ Medical Biology Research Center, Kermanshah University of Medical Sciences, Kermanshah, Iran
}

\begin{abstract}
Aim of the study: We reported the association between interleukin 6 polymorphisms (rs1800796, rs1800795, rs2069837, rs17147230, and rs1800797) and hepatocellular carcinoma (HCC) susceptibility in a meta-analysis.

Material and methods: The studies were retrieved by searching the search terms in Scopus, PubMed, Web of Science, and Cochrane Library databases until June 2020. The analyses were done by RevMan 5.3 software using odds ratios (ORs) and $95 \%$ confidence intervals (Cls) and the analysis of publication bias and sensitivity analyses were performed by CMA 2.0 software.

Results: Searching through the databases, 316 records were retrieved and finally 13 studies were analyzed in the present meta-analysis. For the rs 1800797 polymorphism, there was an elevated risk of AA genotype $(O R=2.68$, $p=0.03)$ in HCC patients compared to healthy controls. Also, there was an elevated risk of $\mathrm{AA}(\mathrm{OR}=3.06, p=0.04)$ and $\mathrm{GA}(\mathrm{OR}=2.61, p=0.005)$ genotypes in HCC patients compared to liver cirrhosis patients. For rs2069837 polymorphism, there was an elevated risk of $\mathrm{GG}$ genotype $(\mathrm{OR}=2.25, p=0.01)$ in $\mathrm{HCC}$ patients compared to healthy controls. For rs 17147230, $\mathrm{T}$ allele $(\mathrm{OR}=1.31, p=0.03)$ and $T$ genotype $(\mathrm{OR}=1.83, p=0.02)$ had elevated risks in HCC patients compared to healthy controls.

Conclusions: The present meta-analysis confirmed that there was an elevated risk of the AA and GA genotypes of rs 1800797 polymorphism and the GG genotype of rs 2069837 , and the T allele and TT genotype of rs 17147230 in HCC.
\end{abstract}

Key words: polymorphism, interleukin 6, hepatocellular carcinoma, hepatitis, cirrhosis.

\section{Address for correspondence:}

Masoud Sadeghi, MSc, Medical Biology Research Center, Kermanshah University of Medical Sciences, Kermanshah, Iran, e-mail: sadeghi_mbrc@yahoo.com

\section{Introduction}

Hepatocellular carcinoma (HCC) is the third leading cause of death from liver cancer worldwide, especially in patients with chronic hepatitis B virus (HBV) and hepatitis $\mathrm{C}$ virus (HCV) infections $[1,2]$ and is more common in developing countries, with a higher prevalence than in developed countries [3]. The incidence of HCC varies widely around the world, but HCC is 3 to 4 times more common in men than women [4]. Different cytokines play an important role in regulating the immune response and defending against viruses. One study has shown that cytokine production in various diseases is related to polymorphisms affecting the cytokine gene [5]. Inflammatory cytokines may have a positive or negative effect on the growth and development of HCC [6]. Interleukin 6 (IL-6) is a multifunctional cytokine that has recently been identified as one of the most important 
compounds in the cancer-related cytokine complex that ultimately leads to systemic immune stimulation along with the suppression of the immune system caused by cancer, which ultimately protects cancer cells [7]. A recent meta-analysis reported elevated serum levels of IL-6 in HCC patients compared to patients with chronic hepatitis $(\mathrm{CH})$ or liver cirrhosis (LC) and healthy controls, which may indicate a significant association of this cytokine with an increased risk of HCC [8]. Studies have shown that polymorphisms in the IL-6 promoter region are included in the pathogenesis of various diseases $[9,10]$. The potential association of $I L-6$ polymorphism with HCC risk has been investigated in many studies. However, the results are highly controversial and not conclusive [11-14]. A meta-analysis with eight studies without subgroup analysis in 2014 that assessed the association of rs 1800795 and rs 1800796 polymorphisms of $I L-6$ with the risk of HCC [15] suggested that the G allele of IL-6 rs 1800795 polymorphism could have an elevated HCC risk; however, the rs 1800796 polymorphism was not associated with HCC risk. Based on our knowledge, there was no meta-analysis about other polymorphisms of $I L-6$ (rs2069837, rs17147230, and rs1800797) in the literature. The aim of the present meta-analysis was to evaluate the association between IL-6 polymorphisms (rs1800796, rs1800795, rs2069837, rs17147230, and rs1800797) and susceptibility to HCC with more studies.

\section{Material and methods}

\section{Search strategies}

One reviewer (M.S.) retrieved the studies of the meta-analysis by the search terms ("interleukin 6" or "IL-6") and ("hepatocellular carcinoma" or "HCC" or "liver cancer") and ("polymorphism" or "variant" or "genotype" or "allele") in Scopus, PubMed, Web of Science, and Cochrane Library databases from their start date to June 2020.

\section{Study selection and selection criteria}

The studies on the association between IL-6 polymorphisms and HCC susceptibility were selected without restrictions of language, period, gender, and age. The studies were analyzed if they: 1) were case-control reporting the patients with $\mathrm{LC}, \mathrm{CH}$, or healthy controls as the control group; 2) included IL-6 polymorphisms of rs1800796, rs1800795, rs2069837, rs17147230, and rs1800797; 3) reported HCC diagnosis pathologically; 4) reported healthy control subjects without systematic diseases; 5) reported HCC patients with/without HBV or HCV infections.
The studies were excluded if they did not have the required data regarding genotype distributions, meta-analyses, and conference papers. One reviewer (O.E.A.) checked the relevant articles based on the eligibility criteria.

\section{Data extraction}

The studies involved in the meta-analysis were checked by one reviewer (M.S.) for extracting the relevant data. Another author (O.E.A.) re-evaluated the data. Disagreements were resolved by the third reviewer (P.O.).

\section{Statistical analyses}

The heterogeneity percentage between the studies was evaluated by the Cochrane Q test and $I^{2}$ statistic. The analyses were done by Review Manager 5.3 (RevMan 5.3, The Cochrane Collaboration, Oxford, United Kingdom) with a random-effects model using odds ratios (ORs) and 95\% confidence intervals (CIs) which, in the case of lack of heterogeneity $\left(I^{2}<50 \%\right.$, $P_{\mathrm{h}}$ or $\left.P_{\text {heterogeneity }}>0.1\right)$, led to use of a fixed-effects model. The $p$-value $(2$-sided $)<0.05$ was considered statistically significant. Subgroup analysis based on ethnicity was performed for rs 1800796 polymorphism with sufficient/acceptable studies included in the analysis. The funnel plot analyses with both Begg's and Egger's tests (for evaluation of the publication bias across the studies) and sensitivity analyses (for confirming the stability of the results) - one removed study and cumulative analysis - were performed by Comprehensive Meta-Analysis 2.0 (CMA 2.0) software.

\section{Results}

\section{Study selection}

Searching through four databases, 316 records were retrieved (Fig. 1). After removing duplicates and irrelevant data, 19 full-text articles were evaluated for eligibility. After that, six articles were excluded with reasons (one study mixed HCC and LC patients together; three studies were meta-analyses/systematic reviews; one study reported a new polymorphism of interleukin 6; one study reported rs1800795 between HCC and $\mathrm{CH}$ patients). Finally, 13 studies were included in the present meta-analysis.

\section{Study characteristics}

The characteristics of the 13 studies [11-14, 16-24] are shown in Table 1 . The studies were published from 2003 to 2020 . Six studies $[11,13,17,22-24]$ were re- 
ported from China, two $[18,19]$ from Italy, one [20] from the USA, one [21] from Korea, one [12] from Egypt, and one [16] from Pakistan. Out of 13 studies, seven included [11, 13, 17, 21-24] Asian, five [12, 14, $16,18,19]$ Caucasian, and one mixed [20] ethnicities. Other characteristics such as the source of controls and sample size of each study are shown in Table 1.

Table 2 illustrates the prevalence of genotypes of the IL-6 polymorphisms (rs1800796, rs1800795, rs2069837, rs17147230, and rs1800797) in the HCC group compared to $\mathrm{LC}, \mathrm{CH}$, or healthy control groups. The control groups in four studies showed a deviation from Hardy-Weinberg equilibrium (HWE) (HCC vs. LC for rs 1800795 in one study [19], HCC vs. LC and HCC vs. healthy control for rs1800796 in two $[12,14]$ and one [14] studies, respectively, HCC vs. healthy control for rs2069837 in one study [16], and HCC vs. healthy control for rs17147230 in one study [16]).

\section{Pooled analysis}

The pooled ORs of the association between the IL- 6 polymorphisms and HCC risk have been abstracted in

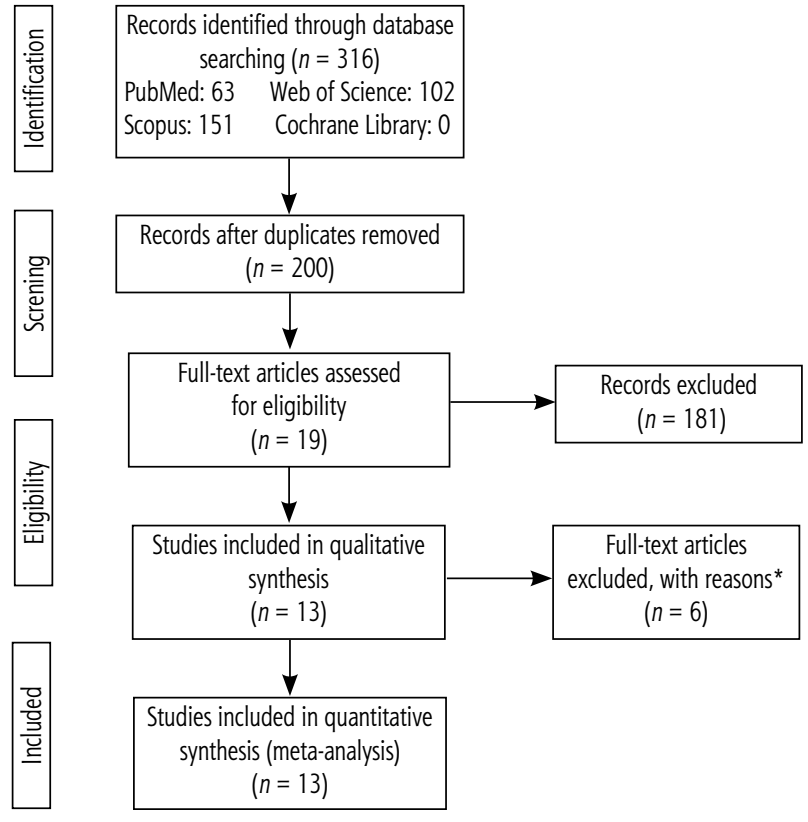

*1 study mixed hepatocellular carcinoma and cirrhosis patients together. 3 studies were meta-analyses/systematic reviews. 1 study reported new polymorphism of interleukin-6. 1 study reported rs 1800795 between hepatocellular carcinoma and hepatitis patients.

Fig. 1. Flowchart of the study selection

Table 1. Characteristics of the studies included in the meta-analysis ( $\mathrm{HCC}$ vs. $\mathrm{LC} / \mathrm{CH} / \mathrm{HC}$ )

\begin{tabular}{|c|c|c|c|c|}
\hline First author, publication year & Country & Ethnicity & Source of controls & Sample size (case/control) \\
\hline \multirow[t]{2}{*}{ Park, 2003 [21] } & Korea & Asian & LC & $221 / 475$ \\
\hline & & & $\mathrm{CH}$ & $221 / 280$ \\
\hline \multirow[t]{2}{*}{ Falleti, 2009 [18] } & Italy & Caucasian & $\mathrm{LC}$ & $66 / 153$ \\
\hline & & & $\mathrm{HC}$ & $66 / 236$ \\
\hline Ognjanovic, 2009 [20] & USA & Mixed & $\mathrm{HC}$ & $117 / 221$ \\
\hline \multirow[t]{2}{*}{ Giannitrapani, 2011 [19] } & Italy & Caucasian & $\mathrm{LC}$ & $105 / 95$ \\
\hline & & & $\mathrm{HC}$ & $105 / 98$ \\
\hline \multirow[t]{2}{*}{ Qiu, 2011 [13] } & China & Asian & $\mathrm{CH}$ & $381 / 340$ \\
\hline & & & $\mathrm{HC}$ & $381 / 359$ \\
\hline \multirow[t]{2}{*}{ Liu, 2012 [11] } & China & Asian & $\mathrm{CH}$ & $500 / 286$ \\
\hline & & & $\mathrm{HC}$ & $500 / 304$ \\
\hline \multirow[t]{3}{*}{ Tang, 2013 [22] } & China & Asian & $\mathrm{LC}$ & $148 / 265$ \\
\hline & & & $\mathrm{CH}$ & $148 / 292$ \\
\hline & & & $\mathrm{HC}$ & $148 / 153$ \\
\hline Bei, 2014 [17] & China & Asian & $\mathrm{HC}$ & $720 / 784$ \\
\hline Saxena, 2014 [14] & India & Caucasian & $\mathrm{HC}$ & $61 / 83$ \\
\hline Tang, 2014 [23] & China & Asian & $\mathrm{CH}$ & $505 / 395$ \\
\hline Zheng, 2015 [24] & China & Asian & $\mathrm{HC}$ & $205 / 209$ \\
\hline \multirow[t]{2}{*}{ Madkour, 2018 [12] } & Egypt & Caucasian & $\mathrm{HC}$ & $60 / 55$ \\
\hline & & & $\mathrm{CH}$ & $60 / 50$ \\
\hline Adnan, 2020 [16] & Pakistan & Caucasian & $\mathrm{CH}$ & $72 / 38$ \\
\hline
\end{tabular}

HCC - hepatocellular carcinoma, LC - liver cirrhosis, $\mathrm{CH}$ - chronic hepatitis, HC - healthy control 
Table 2. Prevalence of genotypes of the interleukin-6 polymorphisms

\begin{tabular}{lcccccc}
\hline $\begin{array}{l}\text { First author, } \\
\text { publication year }\end{array}$ & Polymorphism & HCC & LC & CH & HC & $\begin{array}{c}\text { P-value of HWE for control } \\
\text { group(s) }\end{array}$ \\
\hline Park, 2003 [21] & rs1800796 & $117 / 92 / 12$ & $391 / 261 / 44$ & $175 / 88 / 17$ & NA & $0.959 / 0.193$ \\
\hline Falleti, 2009 [18] & rs1800796 & 0/9/57 & $1 / 17 / 135$ & NA & $0 / 33 / 203$ & $0.569 / 0.248$ \\
\cline { 2 - 7 } & rs1800795 & $1 / 35 / 30$ & $18 / 63 / 72$ & NA & $31 / 103 / 102$ & $0.463 / 0.536$ \\
\cline { 2 - 7 } & rs1800797 & $2 / 34 / 30$ & $18 / 62 / 73$ & NA & $30 / 99 / 107$ & $0.391 / 0.348$ \\
\hline Ognjanovic, 2009 [20] & rs1800795 & $71 / 46 *$ & NA & NA & $103 / 118 *$ & NA \\
\hline Giannitrapani, 2011 [19] & rs1800795 & $63 / 36 / 6$ & $66 / 21 / 8$ & NA & $51 / 37 / 10$ & $0.004 / 0.401$ \\
\hline Qiu, 2011 [13] & rs1800796 & $259 / 110 / 12$ & NA & $210 / 107 / 23$ & $241 / 105 / 13$ & $0.071 / 0.710$ \\
\hline Liu, 2012 [11] & rs1800796 & $315 / 169 / 16$ & NA & $206 / 74 / 6$ & $193 / 99 / 12$ & $0.829 / 0.875$ \\
\hline Tang, 2013 [22] & rs1800796 & $90 / 51 / 7$ & $101 / 46 / 6$ & $194 / 87 / 11$ & $176 / 78 / 11$ & $0.791 / 0.749 / 0.529$ \\
\hline Bei, 2014 [17] & rs1800796 & $485 / 213 / 22$ & NA & NA & $523 / 232 / 29$ & 0.605 \\
\hline Saxena, 2014 [14] & rs1800796 & $20 / 25 / 16$ & $6 / 38 / 19$ & $16 / 41 / 8$ & $33 / 8 / 42$ & $0.039 / 0.415 /<0.001$ \\
\cline { 2 - 7 } & rs1800797 & $28 / 26 / 5$ & $40 / 18 / 3$ & NA & $75 / 55 / 8$ & $0.604 / 0.559 / 0.614$ \\
\hline Tang, 2014 [23] & rs1800796 & $310 / 173 / 22$ & NA & $267 / 118 / 10$ & NA & 0.473 \\
\hline Zheng, 2015 [24] & rs2069837 & $92 / 113 / 21$ & NA & NA & $111 / 98 / 11$ & 0.068 \\
\cline { 2 - 7 } & rs17147230 & $80 / 107 / 39$ & NA & NA & $90 / 109 / 21$ & 0.141 \\
\hline Madkour, 2018 [12] & rs1800796 & $4 / 11 / 45$ & NA & $3 / 9 / 43$ & $5 / 14 / 31$ & $\mathbf{0 . 0 2 3 / 0 . 1 0 0}$ \\
\hline Adnan, 2020 [16] & rs2069837 & $14 / 48 / 10$ & NA & NA & $24 / 6 / 8$ & $<0.001$ \\
\hline
\end{tabular}

*Data show GC + CC genotypes. Bolded numbers are statistically significant $(p<0.05)$.

HWE - Hardy-Weinberg equilibrium, NA - not available, HCC - hepatocellular carcinoma, LC - liver cirrhosis, CH - chronic hepatitis, HC - healthy control. Arrangement of genotypes: rs2069837 (AA/AG/GG), rs17147230 (AA/AT/TT), rs1800796 (CC/CG/GG), rs1800795 (GG/GC/CC), rs 1800797 (GG/GA/AA)

Table 3. The funnel plots were not shown due to the large numbers as well as the format of the journal. The results just showed the significant association between three polymorphisms and HCC risk without heterogeneity. For rs1800797 polymorphism, there was an elevated risk of AA genotype $(\mathrm{OR}=2.68,95 \% \mathrm{CI}: 1.09,6.59$, $p=0.03)$ in HCC patients compared to healthy controls. Also, there was an elevated risk of AA $(\mathrm{OR}=3.06,95 \%$ CI: $1.05,8.90, p=0.04)$ and $\mathrm{GA}(\mathrm{OR}=2.61,95 \% \mathrm{CI}$ : $1.33,5.13, p=0.005)$ genotypes in HCC patients compared to LC patients. For rs2069837 polymorphism, there was an elevated risk of GG genotype ( $\mathrm{OR}=2.25$, $95 \%$ CI: 1.18, 4.29, $p=0.01)$ in HCC patients compared to healthy controls. For rs17147230, T allele $(\mathrm{OR}=1.31$, $95 \%$ CI: $1.02,1.67, p=0.03)$ and TT genotype $(\mathrm{OR}=1.83$, $95 \%$ CI: 1.08, 3.09, $p=0.02$ ) had elevated risks in HCC patients compared to healthy controls.

\section{Subgroup analysis}

The subgroup analysis based on ethnicity for evaluation of the association between rs1800796 polymorphism and HCC risk is shown in Table 4. As it illustrates, there was no significant association between rs1800796 polymorphism and HCC risk reporting HCC patients compared to healthy controls or $\mathrm{CH}$ patients $(p>0.05)$.

\section{Sensitivity analysis}

Both "one study excluded" and "cumulative analysis" were performed for rs 1800796 polymorphism and the pooled ORs did not change qualitatively. Therefore, the analyses showed that the pooled ORs under all genetic models were stable and trustworthy. Also, we removed the studies with a deviation of HWE for their controls. Removing one study [14] for the association between rs 1800796 polymorphism and the risk of HCC comparing HCC patients compared to LC patients and healthy controls, the previous pooled results did not change. Also, removing another study [12] for the association between rs1800796 polymorphism and the risk of HCC comparing HCC patients compared to $\mathrm{CH}$ patients, the previous pooled result did not change.

\section{Publication bias}

Figure 2 shows the funnel plots of all genetic models to evaluate the association between HCC risk and rs1800796 
Table 3. Pooled results of association between the interleukin-6 polymorphisms and hepatocellular carcinoma risk

\begin{tabular}{|c|c|c|c|c|c|c|}
\hline \multirow{2}{*}{$\begin{array}{l}\text { Polymorphism } \\
\text { (N) }\end{array}$} & \multirow[t]{2}{*}{ Comparison } & Allele & Homozygote & Heterozygote & Recessive & Dominant \\
\hline & & $\begin{array}{l}\text { OR }(95 \% \mathrm{Cl}) \\
p \text {-value, } P\left(P_{h}\right)\end{array}$ & $\begin{array}{l}\text { OR }(95 \% \mathrm{Cl}) \\
p \text {-value, } P^{2}\left(P_{h}\right)\end{array}$ & $\begin{array}{l}\text { OR }(95 \% \mathrm{Cl}) \\
p \text {-value, } I^{2}\left(P_{h}\right)\end{array}$ & $\begin{array}{l}\text { OR }(95 \% \mathrm{Cl}) \\
p \text {-value, } P^{2}\left(P_{h}\right)\end{array}$ & $\begin{array}{l}\text { OR }(95 \% \mathrm{Cl}) \\
p \text {-value, } P^{2}\left(P_{h}\right)\end{array}$ \\
\hline rs 1800 & HCC vs. HC & $\begin{array}{c}0.93(0.83,1.05), 0.25 \\
36 \%(0.15)\end{array}$ & $\begin{array}{c}0.86(0.69,1.19) \\
0.37,0 \%(0.81)\end{array}$ & $\begin{array}{l}1.15(0.89,1.49) \\
0.28,57 \%(0.04)\end{array}$ & $\begin{array}{l}1.03(0.90,1.18), \\
0.69,0 \%(0.79)\end{array}$ & $\begin{array}{l}0.83(0.63,1.10), \\
0.20,40 \%(0.12)\end{array}$ \\
\hline rs 180 & HCC vs. LC & $\begin{array}{c}1.00(0.83,1.20), 0.96 \\
47 \%(0.13)\end{array}$ & $\begin{array}{l}0.75(0.76,1.24) \\
0.26,39 \%(0.18)\end{array}$ & $\begin{array}{l}0.83(0.42,1.64) \\
0.59,72 \%(0.01)\end{array}$ & $\begin{array}{l}0.83(0.44,1.58) \\
0.57,72 \%(0.01)\end{array}$ & $\begin{array}{c}0.88(0.59,1.32), \\
0.54,0 \%(0.95)\end{array}$ \\
\hline rs 180 & $\mathrm{H}$ & $\begin{array}{c}1.13(0.92,1.39), 0.24 \\
62 \%(0.01)\end{array}$ & $\begin{array}{l}1.09(0.79,1.51) \\
0.60,42 \%(0.11)\end{array}$ & & $\begin{array}{l}1,1.49) \\
\%(0.02)\end{array}$ & $\begin{array}{l}1.08(0.80 \\
0.62,49 \%\end{array}$ \\
\hline rs 180 & HCC vs. HC & $\begin{array}{c}0.83(0.62,1.11), 0.22 \\
0 \%(0.40)\end{array}$ & $\begin{array}{l}1.88(0.09,40.24) \\
0.69,86 \%(0.008)\end{array}$ & $\begin{array}{c}2.44(0.17,35.57) \\
0.51,85 \%(0.01)\end{array}$ & $\begin{array}{l}0.92(0.39,2.16) \\
0.85,75 \%(0.02)\end{array}$ & $\begin{array}{l}0.93(0.58,1.51), \\
0.78,29 \%(0.23)\end{array}$ \\
\hline rs 1800 & HCC vs. LC & $\begin{array}{c}0.98(0.71,1.33), 0.88 \\
33 \%(0.22)\end{array}$ & $\begin{array}{c}2.07(0.21,20.52) \\
0.53,74 \%(0.05)\end{array}$ & $\begin{array}{c}3.23(0.62,16.84) \\
0.16,62 \%(0.11)\end{array}$ & $\begin{array}{c}2.79(0.51,15.07) \\
0.23,64 \%(0.09)\end{array}$ & $\begin{array}{c}0.87(0.52,1.45) \\
0.59,0 \%(0.58)\end{array}$ \\
\hline rs1800797 (2) & HCC vs. HC & $\begin{array}{c}1.98(0.76,5.15), 0.16 \\
88 \%(0.003)\end{array}$ & $\begin{array}{c}2.68(1.09,6.59) \\
0.03,0 \%(0.33)\end{array}$ & $\begin{array}{l}2.18(0.55,8.56) \\
0.26,67 \%(0.08)\end{array}$ & $\begin{array}{l}2.09(0.62,7.07), \\
0.24,61 \%(0.11)\end{array}$ & $\begin{array}{c}1.08(0.66,1.77), \\
0.77,0 \%(0.54)\end{array}$ \\
\hline rs1800797 (2) & HCC vs. LC & $\begin{array}{c}1.36(0.95,1.95), 0.09 \\
22 \%(0.26)\end{array}$ & $\begin{array}{c}3.06(1.05,8.90) \\
0.04,0 \%(0.68)\end{array}$ & $\begin{array}{l}2.61(1.33,5.13), \\
0.005,3 \%(0.31)\end{array}$ & $\begin{array}{l}2.31(1.23,4.35) \\
0.010,0 \%(0.69)\end{array}$ & $\begin{array}{c}0.98(0.57,1.67) \\
0.93,0 \%(0.39)\end{array}$ \\
\hline rs2069837 (2) & HCC vs. HC & $\begin{array}{c}1.06(0.26,4.24), 0.94 \\
0.94 \%(<0.0001)\end{array}$ & $\begin{array}{c}2.25(1.18,4.29) \\
0.01,0 \%(0.92)\end{array}$ & $\begin{array}{c}4.13(0.44,38.89) \\
0.22,94 \%(<0.0001)\end{array}$ & $\begin{array}{l}1.89(0.98,3.65) \\
0.06,54 \%(0.14)\end{array}$ & $\begin{array}{l}1.15(0.37,3.58) \\
0.82,69 \%(0.07)\end{array}$ \\
\hline rs 17147230 (2) & HCC vs. HC & $\begin{array}{c}1.31(1.02,1.67), \\
0.03,0 \%(0.54)\end{array}$ & $\begin{array}{c}1.83(1.08,3.09) \\
0.02,0 \%(0.39)\end{array}$ & $\begin{array}{c}11.36(0.05,2579.79) \\
0.38,93 \%(0.0002)\end{array}$ & $\begin{array}{c}2.86(0.53,15.48) \\
0.22,92 \%(0.0004)\end{array}$ & $\begin{array}{c}0.77(0.11,5.26) \\
0.79,92 \%(0.0004)\end{array}$ \\
\hline
\end{tabular}

${ }^{*}$ In recessive model, three studies were included. Bolded numbers are statistically significant $(p<0.05)$. N - number of studies, $O R-$ odds ratio, $C l-$ confidence interval, $P_{h}-P_{h e t}$ HCC - hepatocellular carcinoma, LC - liver cirrhosis, CH - chronic hepatitis, HC - healthy control. Arrangement of genotypes: rs2069837 (AA/AG/GG), rs 17147230 (AA/AT/TT), rs1800796 (CC/CG/GG), rs1800795 (GG/GC/CC), rs1800797 (GG/GA/AA)

Table 4. Pooled results of association between rs 1800796 polymorphisms and hepatocellular carcinoma risk based on ethnicity

\begin{tabular}{|c|c|c|c|c|c|c|}
\hline \multirow{2}{*}{$\begin{array}{l}\text { rs1800796 } \\
\text { polymorphism (N) }\end{array}$} & \multirow[t]{2}{*}{ Comparison } & Allele & Homozygote & Heterozygote & Recessive & Dominant \\
\hline & & $\begin{array}{l}\text { OR }(95 \% \mathrm{Cl}) \\
p \text {-value, }{ }^{2}\left(P_{h}\right)\end{array}$ & $\begin{array}{l}\text { OR }(95 \% \mathrm{Cl}) \\
p \text {-value, }{ }^{2}\left(P_{h}\right)\end{array}$ & $\begin{array}{c}\text { OR }(95 \% \mathrm{Cl}) \\
p \text {-value, } I^{2}\left(P_{h}\right)\end{array}$ & $\begin{array}{l}\text { OR }(95 \% \mathrm{Cl}) \\
p \text {-value, } P^{2}\left(P_{h}\right)\end{array}$ & $\begin{array}{l}\text { OR }(95 \% \mathrm{Cl}) \\
p \text {-value, } I^{2}\left(P_{h}\right)\end{array}$ \\
\hline \multicolumn{7}{|l|}{ Ethnicity } \\
\hline Asian (4) & \multirow[t]{2}{*}{ HCC vs. HC } & $\begin{array}{l}0.93(0.82,1.05) \\
0.26,40 \%(0.17)\end{array}$ & $\begin{array}{c}0.88(0.61,1.27) \\
0.48,0 \%(0.90)\end{array}$ & $\begin{array}{l}1.03(0.89,1.17) \\
0.70,0 \%(0.75)\end{array}$ & $\begin{array}{c}1.06(0.89,1.28) \\
0.51,0 \%(0.64)\end{array}$ & $\begin{array}{c}0.87(0.60,1.25) \\
0.44,0 \%(0.94)\end{array}$ \\
\hline Caucasian (3) & & $\begin{array}{l}1.02(0.60,1.74) \\
0.93,54 \%(0.11)\end{array}$ & $\begin{array}{l}0.82(0.41,1.63) \\
0.57,40 \%(0.20)\end{array}$ & $\begin{array}{c}2.51(0.50,12.58) \\
0.26,69 \%(0.07)\end{array}$ & $\begin{array}{c}0.98(0.79,1.21) \\
0.87,0 \%(0.51)\end{array}$ & $\begin{array}{c}0.86(0.32,2.28) \\
0.75,79 \%(0.008)\end{array}$ \\
\hline \multicolumn{7}{|l|}{ Ethnicity } \\
\hline Asian (5) & HCC vs. CH & $\begin{array}{c}1.16(0.91,1.48) \\
0.24,74 \%(0.004)\end{array}$ & $\begin{array}{l}1.12(0.63,1.99) \\
0.71,59 \%(0.04)\end{array}$ & $\begin{array}{l}1.27(1.00,1.61) \\
0.05,59 \%(0.04)\end{array}$ & $\begin{array}{l}1.23(0.95,1.59) \\
0.12,68 \%(0.02)\end{array}$ & $\begin{array}{l}1.09(0.60,1.98) \\
0.78,59 \%(0.04)\end{array}$ \\
\hline Caucasian (2) & & $\begin{array}{c}1.02(0.68,1.54) \\
0.91,0 \%(0.52)\end{array}$ & $\begin{array}{c}1.27(0.53,3.04) \\
0.59,0 \%(0.46)\end{array}$ & $\begin{array}{c}0.55(0.26,1.15) \\
0.11,0 \%(0.52)\end{array}$ & $\begin{array}{c}0.70(0.35,1.39) \\
0.31,0 \%(0.83)\end{array}$ & $\begin{array}{l}1.29(0.73,2.25) \\
0.38,37 \%(0.21)\end{array}$ \\
\hline
\end{tabular}

For all analyses, there was no statistically significant association $(p>0.05)$.

$N$ - number of studies, $\mathrm{OR}$ - odds ratio, $\mathrm{Cl}$ - confidence interval, $P_{h}-P_{\text {heterogeneity }} \mathrm{HCC}$ - hepatocellular carcinoma, $\mathrm{CH}$ - chronic hepatitis, $\mathrm{HC}$ - healthy control. Arrangement of genotypes: $r 51800796$ (CC/CG/GG)

polymorphism. The $p$-values of Begg's/Egger's tests were $0.452 / 0.524,0.038 / 0.111,0.850 / 0.588,0.188 / 0.044$, and $0.051 / 0.432$ for the allele, homozygote, heterozygote, recessive, and dominant models, respectively, comparing HCC patients to healthy controls. Also, The $p$-values of Begg's/Egger's tests were 0.176/0.807, 0.880/0.611,
$0.652 / 0.475,0.452 / 0.559$, and $0.452 / 0.151$ for the allele, homozygote, heterozygote, recessive, and dominant models, respectively, comparing HCC patients to $\mathrm{CH}$ patients. Begg's test revealed a publication bias for the homozygote model and Egger's test for the recessive model, comparing HCC patients to healthy controls. 

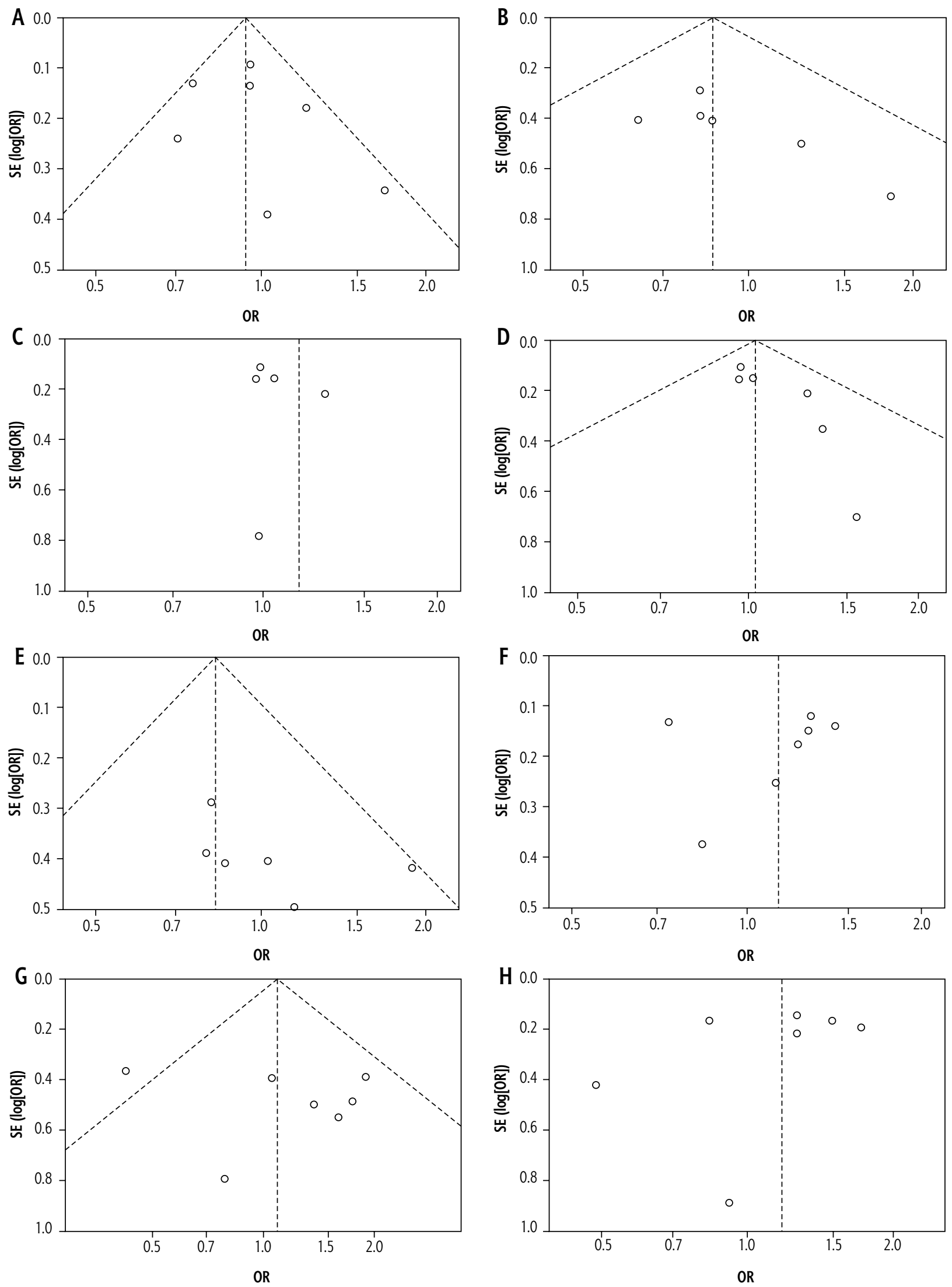

Fig. 2. Funnel plots of association of rs 1800796 polymorphism and risk of hepatocellular carcinoma. A, B, C, D, and E for hepatocellular carcinoma compared to healthy control and $\mathbf{F}, \mathbf{G}, \mathbf{H}, \mathbf{I}$, and J for hepatocellular carcinoma compared to chronic hepatitis, showing allele, homozygote, heterozygote, recessive, and dominant models, respectively 

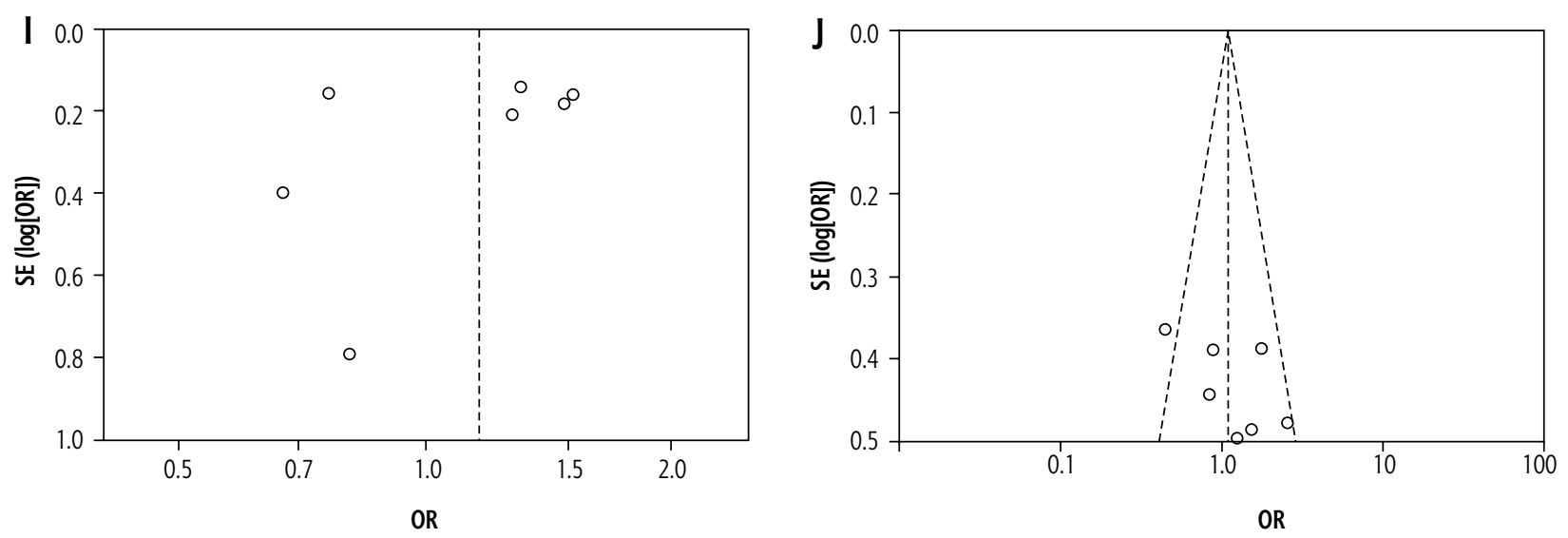

Fig. 2. Cont.

\section{Discussion}

The present meta-analysis reported that among $I L-6$ polymorphisms (rs1800796, rs1800795, rs2069837, rs17147230, and rs1800797), there was an elevated risk of the AA genotype of rs1800797 in HCC patients compared to healthy controls, and an elevated risk of the AA and GA genotypes of rs1800797 polymorphism in HCC compared to LC. There was an elevated risk of the GG genotype of rs2069837 polymorphism in HCC compared to healthy controls and the T allele and TT genotype of rs17147230 had elevated risks in HCC compared to healthy controls.

Chronic inflammation is the result of inflammatory cells adsorbed to the inflamed site, which is associated with the induction of anti-apoptotic mechanisms [25]. Interleukin 6 plays a significant role in this process because of its bilateral and anti-inflammatory cytokine capacity, which in turn supports cell growth and anti-apoptotic activity associated with chronic inflammation [26]. The authors in a meta-analysis concluded that the rs1800796 polymorphism could not be a candidate for susceptibility to HCC, but rs1800795 had an association with a higher risk of HCC. Another metaanalysis assessing $I L-6$ gene polymorphisms and the risk of liver diseases showed that rs1800795, rs1800796, or rs1800797 allele or IL-6 genotypes might be associated with susceptibility to liver diseases with an ethnicdependent base [27]. In our meta-analysis with more studies and with a subgroup analysis on ethnicity, there was no association between two $I L-6$ polymorphisms (rs1800796 and rs1800795) with susceptibility to HCC, whereas rs1800797 polymorphism was associated with the risk of HCC.

The study of Giannitrapani et al. [28] showed the possibility of a genetic link between rs 1800795 polymorphism and some specific liver diseases. This has been ob- served in patients with $\mathrm{HCV}$-related $\mathrm{CH}$, and in $\mathrm{LC}$ and $\mathrm{HCC}$ patients, but not for patients with $\mathrm{HBV}$-related $\mathrm{CH}$. Some studies have shown the potential role of rs 1800796 polymorphism in HBV development and pathogenesis $[14,29]$, but the rs 1800796 polymorphism may not be a determining factor in predicting the outcome of $\mathrm{HCV}$ infection [12]. Therefore, it can be assumed that the differences in the results of studies evaluating the association between $I L-6$ polymorphisms and HCC risk may be due to the difference in the percentage of HCC patients with $\mathrm{HBV}$ or HCV infection. This subject can be considered in the future to obtain better results about this association.

Potential confounding factors, such as sex and ethnicity, can be important for the difference in the association between $I L-6$ polymorphisms and the risk of HCC. One study reported that the protective role of female gender against the occurrence of HCC is mainly effective among carriers of high IL-6 producer phenotypes [18]. Some studies have shown that there were ethnic differences in the frequency of alleles of rs1800795 polymorphism, with lower frequencies in Caucasians than in others [30, 31]. In the present meta-analysis, ethnicity was not a confounding factor for the association of rs1800796 polymorphism and HCC risk, which may be because there were low numbers of studies included in each ethnicity.

There were several limitations for this meta-analysis: 1) a low number of studies in each analysis; 2) simultaneous presence of viral infections in HCC patients; 3 ) the sample size in some of the studies was small; 4) a number of studies showed deviations from HWE; 5) existence of publication bias.

\section{Conclusions}

The findings of the present meta-analysis showed that there was an elevated risk of the AA and GA genotypes of rs1800797 polymorphism and the GG geno- 
type of rs2069837, and the T allele and TT genotype of rs17147230 in HCC. Future studies need to consider possible confounding factors such as viral infection, sex, and ethnicity and include a larger number of participants.

\section{Disclosure}

The authors declare no conflict of interest.

\section{References}

1. Perz JF, Armstrong GL, Farrington LA, et al. The contributions of hepatitis B virus and hepatitis $C$ virus infections to cirrhosis and primary liver cancer worldwide. J Hepatol 2006; 45: 529538.

2. Raza S, Clifford G, Franceschi S. Worldwide variation in the relative importance of hepatitis $B$ and hepatitis $C$ viruses in hepatocellular carcinoma: a systematic review. Br J Cancer 2007; 96: 1127-1134

3. Zahran AM, Abdel-Meguid M, Ashmawy AM, et al. Frequency and implications of natural killer and natural killer $\mathrm{T}$ cells in hepatocellular carcinoma. Egypt J Immunol 2018; 25: 45-52.

4. Nordenstedt $\mathrm{H}$, White DL, El-Serag HB. The changing pattern of epidemiology in hepatocellular carcinoma. Digest Liver Dis 2010; 42: S206-S214.

5. Lu Y, Bao JG, Deng Y, et al. Role of IL-18 gene promoter polymorphisms, serum IL-18 levels, and risk of hepatitis B virus-related liver disease in the Guangxi Zhuang population: a retrospective case-control study. Asian Pac J Cancer Prev 2015; 16: 6019-6026.

6. Yang JD, Nakamura I, Roberts LR, et al. The tumor microenvironment in hepatocellular carcinoma: current status and therapeutic targets. Semin Cancer Biol 2011; 21: 35-43.

7. Lippitz BE, Harris RA. Cytokine patterns in cancer patients: A review of the correlation between interleukin 6 and prognosis. Oncoimmunology 2016; 5: e1093722.

8. Shakiba E, Ramezani M, Sadeghi M. Evaluation of serum interleukin-6 levels in hepatocellular carcinoma patients: a systematic review and meta-analysis. Clin Exp Hepatol 2018; 4: 182-190.

9. Argilés JM, Busquets S, López-Soriano FJ. Cytokines as mediators and targets for cancer cachexia. The link between inflammation and cancer, Springer 2006; 199-217.

10. Nishimura M, Matsuoka M, Maeda M, et al. Association between interleukin-6 gene polymorphism and human T-cell leukemia virus type I associated myelopathy. Hum Immunol 2002; 63: 696-700

11. Liu S, Qiu X, Zeng X, et al. Relationship between IL6-572G/C polymorphism and hepatocellular carcinoma in men. Zhonghua Gan Zang Bing Za Zhi 2012; 20: 463-467.

12. Madkour B, Gad A, Hamdy MS, et al. Interleukin-6-572 promoter gene polymorphism and its association with chronic hepatitis C-induced hepatocellular carcinoma: an Egyptian study. Comp Clin Path 2018; 27: 161-165.

13. Qiu XQ, Bei CH, Yu HP, et al. Study on the relationship between single-nucleotide polymorphisms in IL-6, IL-10 genes and HBV-related hepatocellular carcinoma. Zhonghua Gan Zang Bing Za Zhi 2011; 32: 510-513.

14. Saxena R, Chawla YK, Verma I, et al. IL-6 (-572/-597) polymorphism and expression in HBV disease chronicity in an Indian population. Am J Hum Biol 2014; 26: 549-555.

15. Liu Y, Gao SJ, Du BX, et al. Association of IL-6 polymorphisms with hepatocellular carcinoma risk: evidences from a meta-analysis. Tumor Biol 2014; 35: 3551-3561.
16. Adnan F, Khan NU, Iqbal A, et al. Interleukin-6 polymorphisms in HCC patients chronically infected with HCV. Infect Agents Cancer 2020; 15: 1-7.

17. Bei $\mathrm{CH}, \mathrm{Bai} \mathrm{H}, \mathrm{Yu} \mathrm{HP}$, et al. Combined effects of six cytokine gene polymorphisms and SNP-SNP interactions on hepatocellular carcinoma risk in Southern Guangxi, China. Asian Pac J Cancer Prev 2014; 15: 6961-6967.

18. Falleti E, Fabris C, Toniutto P, et al. Interleukin-6 polymorphisms and gender: relationship with the occurrence of hepatocellular carcinoma in patients with end-stage liver disease. Oncology 2009; 77: 304-313.

19. Giannitrapani L, Soresi M, Giacalone A, et al. IL-6 -174G/C polymorphism and IL-6 serum levels in patients with liver cirrhosis and hepatocellular carcinoma. OMICS 2011; 15: 183-186.

20. Ognjanovic S, Yuan JM, Chaptman AK, et al. Genetic polymorphisms in the cytokine genes and risk of hepatocellular carcinoma in low-risk non-Asians of USA. Carcinogenesis 2009; 30: 758-762.

21. Park BL, Lee HS, Kim YJ, et al. Association between interleukin 6 promoter variants and chronic hepatitis B progression. Exp Mol Med 2003; 35: 76-82.

22. Tang S, Liu Z, Zhang Y, et al. Rather than Rs 1800796 polymorphism, expression of interleukin- 6 is associated with disease progression of chronic HBV infection in a Chinese Han population. Dis Markers 2013; 35: 799-805.

23. Tang S, Yuan Y, He Y, et al. Genetic polymorphism of interleukin-6 influences susceptibility to HBV-related hepatocellular carcinoma in a male Chinese Han population. Hum Immunol 2014; 75: 297-301.

24. Zheng X, Han C, Shan R, et al. Association of interleukin-6 polymorphisms with susceptibility to hepatocellular carcinoma. Int J Clin Exp Med 2015; 8: 6252-6256.

25. Smith AJ, D’Aiuto F, Palmen J, et al. Association of serum interleukin- 6 concentration with a functional IL-6 $-6331 \mathrm{~T}>\mathrm{C}$ polymorphism. Clin Chem 2008; 54: 841-850.

26. Ishihara K, Hirano T. IL-6 in autoimmune disease and chronic inflammatory proliferative disease. Cytokine Growth Factor Rev 2002; 13: 357-368.

27. Wang X, Yan Z, Ye Q. Interleukin-6 gene polymorphisms and susceptibility to liver diseases: a meta-analysis. Medicine (Baltimore) 2019; 98: e18408.

28. Giannitrapani L, Soresi M, Balasus D, et al. Genetic association of interleukin-6 polymorphism $(-174 \mathrm{G} / \mathrm{C})$ with chronic liver diseases and hepatocellular carcinoma. World J Gastroenterol 2013; 19: 2449-9455.

29. Chang L, Lan T, Wu L, Li C, et al. The association between three IL-6 polymorphisms and HBV-related liver diseases: a meta-analysis. Int J Clin Exp Med 2015; 8: 17036-17045.

30. Cox ED, Hoffmann SC, DiMercurio BS, et al. Cytokine polymorphic analyses indicate ethnic differences in the allelic distribution of interleukin-2 and interleukin-61. Transplantation 2001; 72: 720-726.

31. Meenagh A, Williams F, Ross OA, et al. Frequency of cytokine polymorphisms in populations from western Europe, Africa, Asia, the Middle East and South America. Hum Immunol 2002; 63: 1055-1061. 